\title{
Perancangan Tracking Device Dan Kendali Pada Kendaraan Bermotor Menggunakan GPS Terintegrasi Internet Of Things
}

\author{
M Dandy Aprillah \\ Politeknik Negeri Sriwijaya \\ Jln. Srijaya Negara, Bukit \\ Besar, Kec. Ilir Bar. I, Kota \\ Palembang, Sumatera \\ Selatan 30139 \\ mdandyaprillah@gmail.com
}

\author{
Martinus Mujur Rose \\ Politeknik Negeri Sriwijaya \\ Jln. Srijaya Negara, Bukit \\ Besar, Kec. Ilir Bar. I, Kota \\ Palembang, Sumatera \\ Selatan 30139 \\ mujurrose@yahoo.com
}

\author{
Nasron \\ Politeknik Negeri Sriwijaya \\ Jln. Srijaya Negara, Bukit \\ Besar, Kec. Ilir Bar. I, Kota \\ Palembang, Sumatera \\ Selatan 30139 \\ nasron6819@gmail.com
}

\begin{abstract}
Motorcycles are one of the objects that are very prone to be stolen, anticipation of theft is not enough just to install a safety lock, but it needs to be equipped with monitoring and controlling systems to reduce theft of motorcycles because motorcycles are generally not equipped with GPS (Global Positioning System). In this final task, a Tracking Device or tracking tool is designed that can work in IoT. IoT (Internet of Things) is a computational concept of everyday objects connected to the internet and able to identify themselves to other devices. NodeMCU ESP8266 and Android smartphone are used as tracking device controller components. The signal or data obtained in the form of vehicle position coordinate data can be seen in googlemaps, and this tool is equipped with a relay that serves as a switch to turn the stolen motor on or off remotely. The test result of this tool, the user can control the motor from a very long distance as long as the device and the user still get internet access, the user can only give one command every 15 seconds, be it a command asking for the coordinates of the position of the vehicle or a command to turn off the motor.
\end{abstract}

Keywords: Android, GPS, Internet of Things, NodeMCU ESP8266

\section{PENDAHULUAN}

Pencurian kendaraan bermotor semakin meningkat setiap harinya khususnya di Indonesia, motor merupakan salah satu objek yang paling banyak dicuri dan sistem pelacakan kendaraan bermotor masih menggunakan sistem manual. Sistem manual yang dimaksud yaitu ketika pemilik kendaraan motor kehilangan kendaraan, pemilik hanya dapat melaporkan ke kantor polisi. Pelacakan kendaraan bermotor yang dilakukan yaitu dengan cara mengumpulkan informasi dari orang-orang disekitar tempat hilangnya motor serta dengan melihat rekaman video CCTV (Closed Circuit Television) di jalan dengan kualitas video yang rendah. Kualitas video yang rendah dapat mempengaruhi akurasi pelacakan kendaraan bermotor, sehingga dapat menghambat proses pencarian motor yang hilang.

Melacak merupakan suatu kegiatan yang dilakukan untuk menemukan suatu barang dengan cara meyelidiki jejak-jejak dari barang yang dilacak. Teknologi informasi (Information Technology) atau biasa di singkat IT, mampu menciptakan sebuah teknologi komunikasi yaitu berupa tracking device atau biasa dikenal sebagai alat pelacak kendaraan berbasis IOT (Internet Of Things) yang dapat membantu dalam kegiatan pencarian kendaaraan yang hilang dengan memanfaatkan teknologi GPS, GPS (Global Positioning System) adalah sistem navigasi berbasis satelit yang dapat menunjukan lokasi dan informasi waktu di segala kondisi cuaca di manapun pada permukaan bumi selama mendapat jangkauan dari minimal empat buah satelit GPS. Perangkat GPS akan menerima sinyal yang dipancarkan oleh satelit GPS. Dengan menghitung berbagai sinyal yang dipancarkan oleh beberapa satelit GPS tersebut, perangkat GPS dapat mengetahui perkiraan posisi perangkat GPS dalam koordinat lintang dan bujur. Maka suatu ketika sepeda motor tersebut hilang karena dicuri atau karena berbagai hal, sepeda motor tersebut dapat dengan mudah ditemukan kembali. Selain dilengkapi dengan GPS, perangkat tracking device juga dilengkapi dengan relay yang berfungsi untuk mematikan ataupun menghidupkan motor.

\section{TEORI DASAR}

NodeMCU ESP8266 merupakan modul wifi yang berfungsi sebagai perangkat tambahan mikrokontroler seperti Arduino agar dapat terhubung langsung dengan wifi dan membuat koneksi TCP/IP. Modul ini membutuhkan daya sekitar $3.3 \mathrm{v}$ dengan memiliki tiga mode wifi yaitu Station, Access Point dan Both. Modul ini juga dilengkapi dengan prosesor, memori dan GPIO dimana jumlah pin bergantung dengan jenis ESP8266 yang kita gunakan. Sehingga modul ini bisa berdiri sendiri tanpa menggunakan mikrokontroler apapun karena sudah memiliki perlengkapan layaknya mikrokontroler.

Firmware default yang digunakan oleh perangkat ini menggunakan AT Command, selain itu ada beberapa Firmware SDK yang digunakan oleh perangkat ini berbasis opensource yang diantaranya adalah sebagai berikut. Menurut data sheet yang ada, 
modul ini membutuhkan daya sekitar 3.3v dengan memiliki tiga mode wifi yaitu Station, Access Point dan Access Piont Station. Modul ini juga dilengkapi dengan GPIO dimana jumlah pin bergantung dengan jenis ESP8266 yang kita gunakan sehingga modul ini bisa berdiri sendiri tanpa menggunakan mikrokontroler apapun [1].

Power bank merupakan perangkat yang mampu menyimpan daya hingga kapasitas tertentu dan bisa digunakan sebagai alat bantu untuk mensuplai daya pada produk tertentu. Powerbank dapat digambarkan seperti baterai yang mampu memberikan daya pada gadget tertentu. Power bank didesain sedemikian rupa sehingga dapat dimanfaatkan untuk beberapa jenis gadget, dari smartphone, tablet, hingga kamera digital Fungsi atau manfaat kegunaan power bank untuk gadget sebenarnya mirip dengan baterai cadangan. Artinya, powerbank ini dapatlah untuk dimanfaatkan sebagai baterai utama ketika henphone atau gadget yang kita miliki tersebut kehabisan tenaga. Dengan kemampuan tentusaja powerbank dapat menyimpan sesuai dengan keadaan atau kapasitas masing-masing, power bank juga bahkan dapat digunakan untuk beberapa jam yang melebihi daya tahan pada baterai utama [2].

GPS (Global Positiong System) adalah suatu sistem navigasi menggunakan lebih dari 24 satelit MEO (Medium Earth Orbit atau Middle Earth Orbit)yang mengelilingi bumi sehingga penerimapenerima sinyal di permukaan bumi dapat menangkap sinyalnya. GPS mengirimkan sinyal gelombang mikro ke Bumi. Sinyal ini diterima oleh alat penerima di permukaan, dan digunakan untuk menentukan letak, kecepatan,arah, dan waktu [3].

Relay berfungsi untuk mengontrol arus listrik dengan memberikan tegangan dan arus pada koil, dengan relay arus listrik dapat diputus atau dihubungkan ke perangkat Internet of Things, ketika pengguna menginginkan menyalakan kendaraan maka NodeMCU akan mengirim sinyal hight ke pin kontrol relay dan ketika relay menerima sinyal hight maka relay akan menutup sirkuit dari rangkaian terkontrol dan relay berfungsi sebagai saklar kendaraan [4].

MiFi adalah nama yang diberikan pada sebuah perangkat wireless router yang berperan sebagai WiFi Hotspot . MiFi ini merupakan kependekan dari Mobile Wi-FI. MiFi merupakan sebuah perangkat hotspot wifi untuk membagikan layanan internet (sharing) yang akses internetnya didapat dari jaringan seluler lalu disebar kepada beberapa perangkat penerima wifi seperti smartphone, laptop hingga komputer. Pada intinya MiFi ini ialah perangkat yang bisa melakukan sharing koneksi internet secara wireless (tanpa kabel), dimana sumber layanan internetnya didapat dengan berlangganan menggunakan provider layanan internet dan telekomunikasi seluler [5].

Smartphone adalah telepon genggam yang mempunyai kemampuan dengan pengunaan dan fungsi yang menyerupai komputer. Belum ada standar pabrik yang menentukan arti ponsel cerdas. Bagi beberapa orang, ponsel cerdas merupakan telepon yang bekerja menggunakan seluruh perangkat lunak sistem operasi yang menyediakan hubungan standar dan mendasar bagi pengembang aplikasi. Bagi yang lainnya, ponsel cerdas hanyalah merupakan sebuah telepon yang menyajikan fitur canggih seperti surel (surat elektronik), internet dan kemampuan membaca buku elektronik (e-book) atau terdapat papan ketik (baik sebagaimana jadi maupun dihubung keluar) dan penyambung VGA. Dengan kata lain, ponsel cerdas merupakan komputer kecil yang mempunyai kemampuan sebuah telepon [6].

LCD adalah suatu jenis media tampilan yang menggunakan kristal cair sebagai penampil utama. LCD (liquid crystal display) bisa memunculkan gambar atau dikarenakan terdapat banyak sekali titik cahaya (piksel) yang terdiri dari satu buah kristal cair sebagai titik cahaya. Walau disebut sebagai titik cahaya, namun Kristal cair ini tidak memancarkan cahaya sendiri. Sumber cahaya di dalam sebuah perangkat LCD (liquid crystal display) adalah lampu neon berwarna putih di bagian belakang susunan kristal cair tadi. Titik cahaya yang jumlahnya puluhan ribu bahkan jutaan inilah yang membentuk tampilan citra. Kutub kristal cair yang dilewati arus listrik akan berubah karena pengaruh polarisasi medan magnetic yang timbul dan oleh karenanya akan hanya membiarkan beberapa warna diteruskan sedangkan warna lainnya tersaring [7].

\section{METODE PENELITIAN}

NodeMCU merupakan komponen utama dalam perancangan alat ini. NodeMCU didukung oleh koneksi WiFi yang digunakan untuk menghubungkan modul tersebut ke jaringan internet. Setelah NodeMCU terkoneksi dengan jaringan internet, NodeMCU tersebut akan memerintah modul GPS untuk menerima data berupa titik koordinat. Selanjutnya data tersebut akan dikirimkan menuju android dan Lcd 16x2. Selain memerintah modul GPS, NodeMCU juga bisa memberikan perintah kepada relay untuk mematikan sepeda motor melalui android

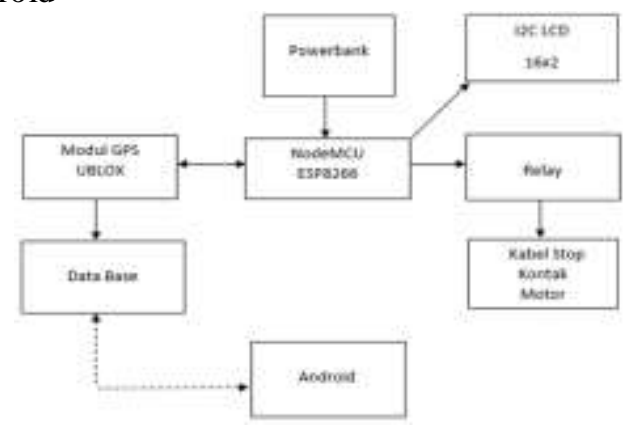

Gambar 1. Diagram Blok Tracking Device 


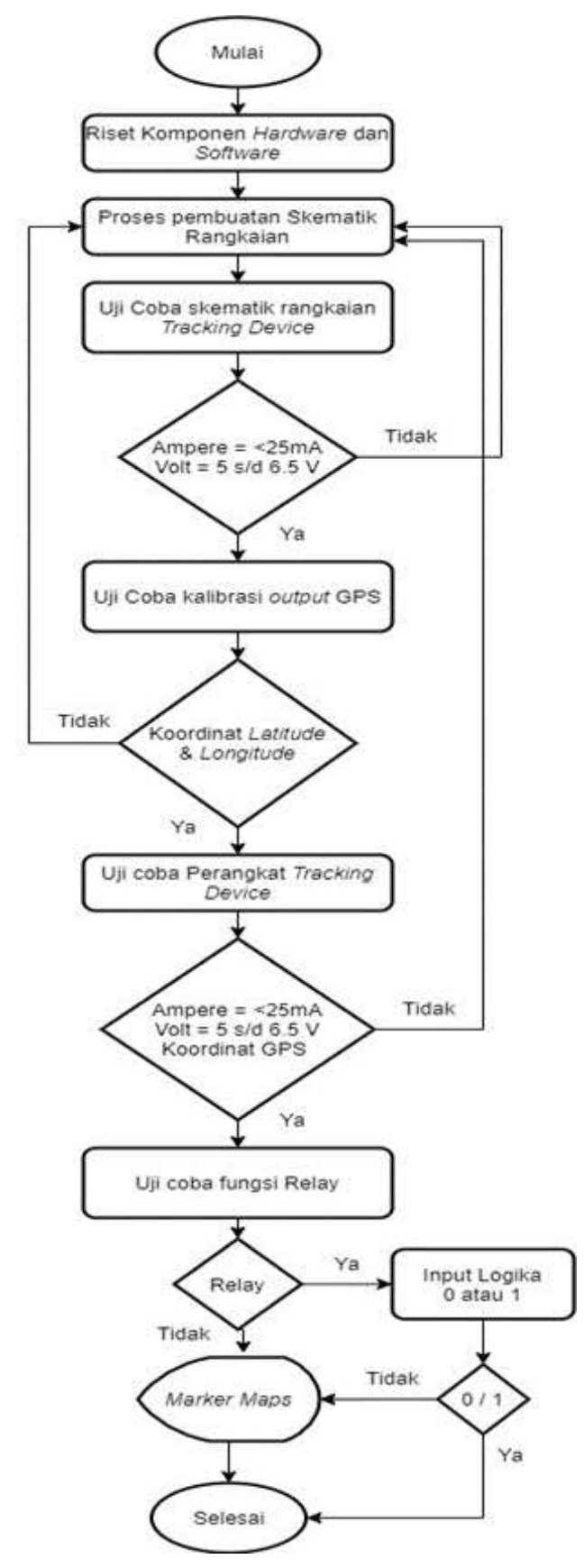

Gambar 2. Flowchart

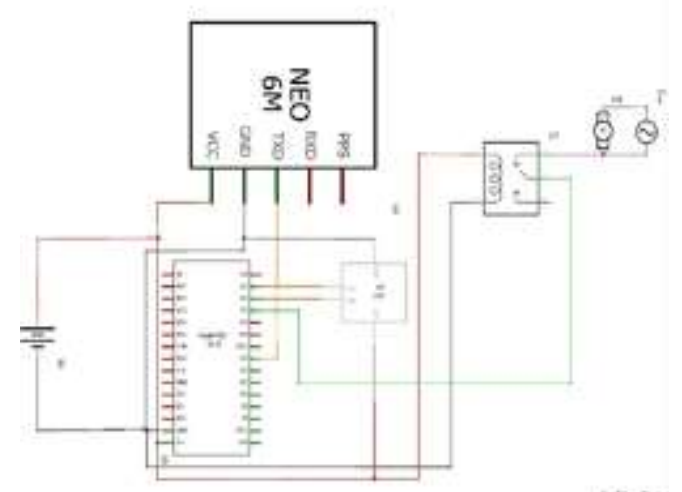

iritzing

Gambar 3. Skematik Rangkaian Tracking Device
Hardware Tracking Device menggunakan GPS Terintegrasi Internet Of Things, Alat ini menggunakan modul Ublox Neo 6MV2, dimana modul Ublox Neo 6MV2 berfungsi untuk mencatat koordinat geografi dengan interval waktu tertentu dari sebuah kendaraan, lalu informasi koordinat kendaraaan tersebut diteruskan oleh NodeMCU ESP8266 dengan bantuan internet dari wifi menuju data base yang disebut ThingSpeak, kemudian Informasi yang ada di ThingSpeak dapat dilihat dan diproses melalui software Tracking Device, apabila user ingin memberikan perintah, user dapat melakukannya melalui software Tracking Device agar dapat diproses oleh ThingSpeak dan ThingSpeak memberikan perintah kepada Hardware agar memproses perintah yang diberikan oleh user melalui Software, baik itu perintah untuk mematikan kendaraan secara otomatis maupun menghidupkan kendaraan tersebut. Hardware Tracking Device akan mengupdate data koordinat posisi sebuah kendaraan setiap 15 detik sekali

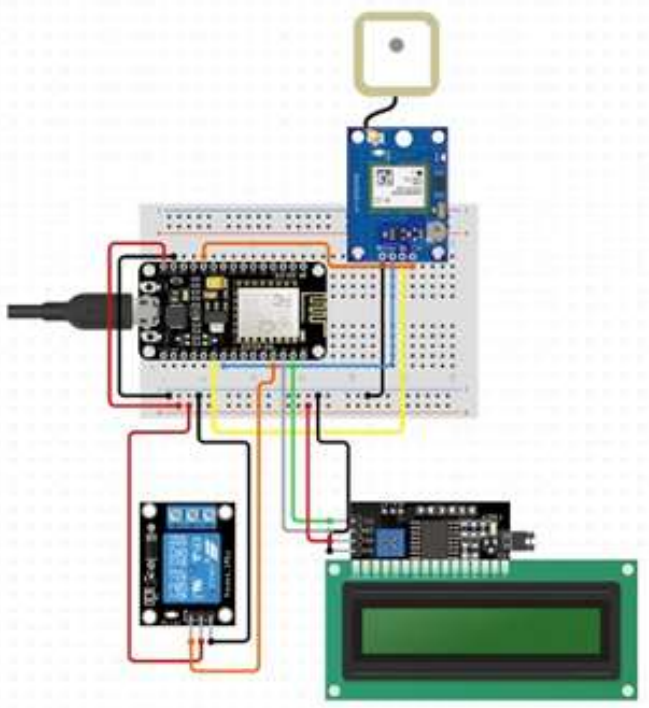

Gambar 4. Desain Rangkaian Tracking Device

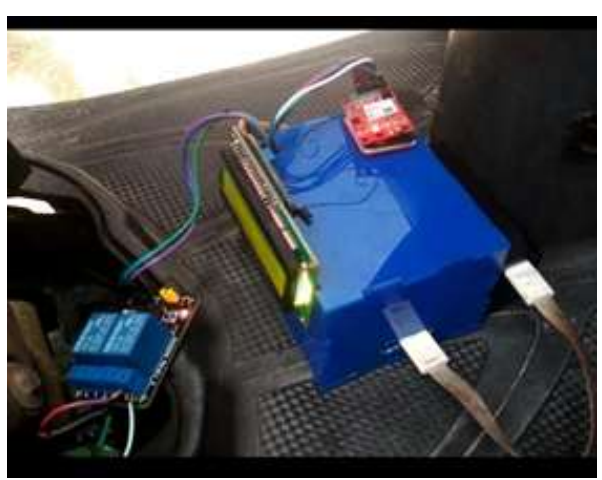

Gambar 5. Hardware Tracking Device

\section{HASIL DAN PEMBAHASAN}

Pada tabel ini terdapat spesifikasi komponenkomponen yang digunakan oleh tracking device. 


\section{Perancangan Tracking Device Dan Kendali Pada Kendaraan Bermotor Menggunakan GPS Terintegrasi}

Internet Of Things

Tabel 1. Spesifikasi Komponen

\begin{tabular}{|c|c|c|}
\hline No & Alut & Spesifilati \\
\hline 1 & $\begin{array}{l}\text { NodeMCt } \\
\text { ESP3266 }\end{array}$ & 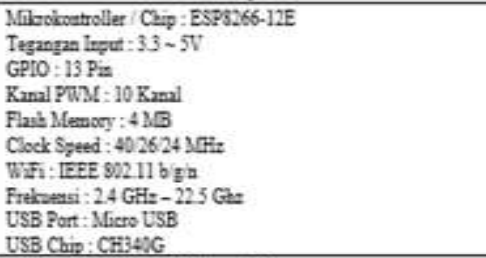 \\
\hline 2 & $\begin{array}{l}\text { GPS Dblox } \\
\text { Neo } \$ \text { LVV }\end{array}$ & 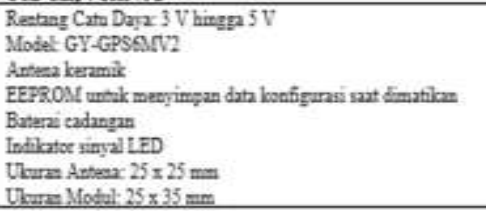 \\
\hline 3 & Relay ICE & 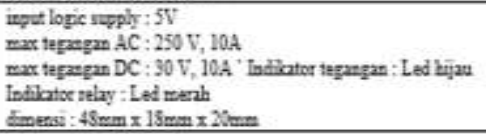 \\
\hline 4 & $\begin{array}{l}\text { Mis } \\
\text { Anhrsenas } \\
\text { MBY }\end{array}$ & 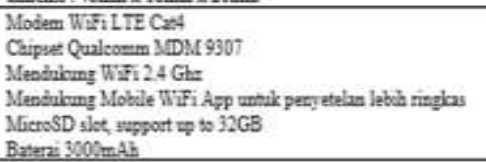 \\
\hline 5 & Pontricank & $5000 \mathrm{mAh}$ \\
\hline 6 & $\begin{array}{l}\text { HP Xiaven } \\
\text { Redrit 4x }\end{array}$ & 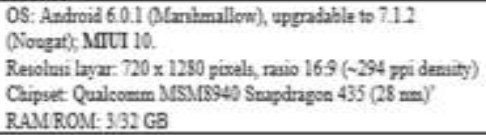 \\
\hline
\end{tabular}

Tabel 2. Data Perbandingan Latitude

\begin{tabular}{|c|c|c|c|c|}
\hline No. & Lokasi & $\begin{array}{c}\text { Latitude } \\
\text { GPS } \\
\text { Aplikasi }\end{array}$ & $\begin{array}{c}\text { Latitude GPS } \\
\text { Googlemaps }\end{array}$ & Error \\
\hline 1. & JM Plaju & -2.990961 & -2.990949 & 0.000012 \\
\hline 2. & UMP & -2.995431 & -2.995433 & 0.000002 \\
\hline 3. & $\begin{array}{c}\text { Jaka } \\
\text { Permai }\end{array}$ & -3.006964 & -3.006969 & 0.000005 \\
\hline 4. & Polsri & -2.983428 & -2.983429 & 0.000001 \\
\hline 5. & T. Karet & -3.005581 & -3.005571 & 0.000010 \\
\hline 6. & \multicolumn{3}{|c|}{ Rata-rata Error } & 0.000006 \\
\hline
\end{tabular}

Tabel 3. Data Perbandingan Longitude

\begin{tabular}{|c|c|c|c|c|}
\hline No. & Lokasi & $\begin{array}{c}\text { Longitude } \\
\text { GPS } \\
\text { Aplikasi }\end{array}$ & $\begin{array}{c}\text { Longitude } \\
\text { GPS }\end{array}$ & $\begin{array}{c}\text { Error } \\
\text { (\%) }\end{array}$ \\
\hline 1. & JM Plaju & 104.793685 & 104.793663 & 0.000022 \\
\hline 2. & UMP & 104.777739 & 104.777730 & 0.000009 \\
\hline 3. & Jaka Pernai & 104.773898 & 104.773953 & 0.000045 \\
\hline 4. & Polsri & 104.732029 & 104.732008 & 0.000021 \\
\hline 5. & T. Karet & 104.797210 & 104.797201 & 0.000009 \\
\hline 6. & & & & 0.000021 \\
\hline
\end{tabular}

Error $=$ Nilai Acuan - Nilai Terukur

Pada tabel 2 dan 3 dapat diketahui bahwa data latitude dan longitude yang diperoleh baik data koordinat dari google maps maupun data GPS pada aplikasi memiliki tingkat error yang kecil. Pengambilan data di luar ruangan (outdoor) membuat GPS dapat bekerja dengan cukup baik dan akurat. Maka dapat dikatakan data GPS yang dikirimkan dari perangkat tracking ke aplikasi mampu berjalan dengan baik.

Tabel 4. Data Perbandingan Longitude

\begin{tabular}{|c|c|c|}
\hline Percobaan Ke- & Jarak & Waktu delay \\
\hline 1 & $1.01 \mathrm{Km}$ & 15 Detik \\
\hline 2 & $1.40 \mathrm{Km}$ & 20 detik \\
\hline 3 & $2.05 \mathrm{Km}$ & 17 detik \\
\hline 4 & $2.59 \mathrm{Km}$ & 20 detik \\
\hline 5 & $2.80 \mathrm{Km}$ & 25 detik \\
\hline 6 & $3.13 \mathrm{Km}$ & 23 detik \\
\hline 7 & $141.1 \mathrm{Km}$ & 1 Menit \\
\hline
\end{tabular}

Respon relay akan diuji ketika motor dan user berada pada jarak yang jauh atau ketika motor dicuri. Sama seperti pada tabel 4. perangkat membutuhkan waktu setidaknya 15 detik untuk dapat mematikan motor dari jarak jauh

Tabel 5. Data Perbandingan Koordinat

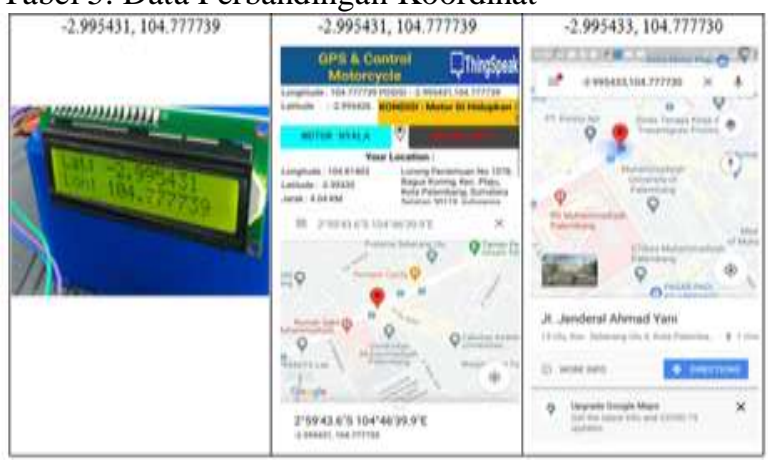

\section{KESIMPULAN}

Berdasarkan dari hasil pengujian dan pengukuran maka penulis menarik kesimpulan bahwa:

1. Tracking Device atau alat pelacak adalah suatu sistem pemantauan jarak jauh yang menggunakan satelit GPS sebagai penentu lokasi kendaraan dengan tepat dan akurat dalam bentuk titik koordinat yang kemudian diimplementasikan ke dalam bentuk peta digital, sehingga dapat dimengerti dengan mudah bagi penggunanya.

2. Komponen-komponen yang digunakan tracking device yaitu NodeMCU ESP8266, Modul GPS Ublox Neo 6M2V, Relay 1 Channel, Powerbank, dan Mifi.

3. Perangkat Tracking Device membutuhkan waktu sekitar 1 menit sampai 3 menit untuk melakukan pengkalibrasian ditempat terbuka setiap kali dihidupkan.

4. Untuk mengirim perintah, user harus menunggu setiap 15 detik sekali agar perangkat dapat 
memproses perintah. Ini dikarenakan sifat dari protokol Thinkspeak, serta data GPS yang diterima di aplikasi android adalah data longitude dan latitude posisi dari kendaraan.

\section{DAFTAR PUSTAKA}

[1] Gunawan, I. Akbar, T. Ilham, G, M. 2020 Prototipe Penerapan Internet Of Things (Iot) Pada Monitoring Level Air Tandon Menggunakan NodeMCU Esp8266 Dan Blynk. Universitas Hamzanwadi. Lombok. Vol. 3 No. 1, Januari 2020, hal 1 - 7

[2] Sulhi, S, M. Ningrum, C, T. Sari, Y. Sari, P, S. Retnowati. 2017. Pemanfaatan Sampah Elektronik Rumah Tangga Sebagai Pembuatan Powerbank. Universitas PGRI Yogyakarta. Yogyakarta.

[3] Rifai, A. 2013. Sistem Informasi Pemantauan Posisi Kendaraan Dinas Unsri Menggunakan Teknologi GPS. Universitas Sriwijaya. Palembang. Jurnal Sistem Informasi (JSI), VOL. 5, NO. 2, Oktober 2013

[4] Susanti, E. Triyono, J. 2016 Prototype Alat IoT (Internet Of Things) Untuk Pengendali Dan Pemantau Kendaraan Secara Realtime. IST AKPRIND. Yogyakarta. Simposium Nasional RAPI XV - 2016 FT UMS

[5] Widayani, Y. 2017. Pengertian Jaringan Wifi. http://eprints.polsri.ac.id/4678/3/FILE\%20III.P DF. Politeknik Negeri Sriwijaya. Palembang. Diakses 10 Agustus 2020.

[6] Rahmanto. Dwi, A. 2013. Semua Tentang Android.

http://marikitaberbagisesama.blogspot.com/201 2/04/semua-tentang-android.html. Diakses 10 Agustus 2020.

[7] Siringoringo, M, R. T. 2015. Perancangan Dan Implementasi Monitoring Kendaraan Bermotor Berbasis GPS Dan SMS. Universitas Telkom. Jakarta 